\title{
Escrevendo cartas: a sexualidade na vida e na formação docente de Biologia
}

\author{
Marco Antonio Leandro Barzano ${ }^{1}$ \\ John Erliton Simão dos Santos ${ }^{2}$
}

\section{RESUMO}

Trata-se de um artigo-carta ou uma carta-artigo. Uma proposta que temos apostado em nosso grupo de pesquisa - RIZOMA - para tentar insubordinar os modos de pesquisar, pensar, escrever, criar, interpretar, dialogar, experimentar.Desde 2015 nosso grupo tem se debruçado nos estudos sobre Narrativas e uma dissertação foi nossa primeira experiência para divulgação que aqui pretendemos apresentar em forma de artigocarta-artigo.Inspirados na perspectiva pós-estruturalista, pretendemos expor não apenas o extrato da dissertação, um pedaço de um capítulo. Não! No presente texto trazemos aquilo que movimentou nossos pensamentos durante o desenvolvimento da pesquisa, ou seja, os rabiscos, os silêncios, as dúvidas, a emoção, o afeto, a dureza, a inconsistência, a potência e por aí vai... O artigo-carta-artigo é o resultado daquilo que dois pesquisadores - orientador e orientando - viveram, (des)construíram por dois anos de trabalho da pesquisa de mestrado, mas também, na continuidade pósdefesa, dois anos depois, durante as reuniões do grupo de pesquisa.

PALAVRAS-CHAVE: Escritas Narrativas. Cartas. Sexualidade. PIBID.

Writing letters: sexuality in life and in the teaching of Biology

\begin{abstract}
It's an article-letter or a letter-article. A proposal that we have placed in our research group - RIZOMA - to try to insubordinate the ways of
\end{abstract}

\footnotetext{
${ }^{1}$ Doutor. Universidade Estadual de Feira de Santana. Feira de Santana. Bahia. Brasil. marco.barzano@gmail.com

${ }^{2}$ Mestre. Universidade Federal da Bahia. Salvador. Bahia.johnerliton_bio@yahoo.com
} 
researching, thinking, writing, creating, interpreting, dialoguing, experiencing. Since 2015 our group has been studying Narratives and a dissertation was our first experience for dissemination that we intend to present here in the form of article-letter-article. Inspired in the poststructuralist perspective, we intend to expose not only the extract of the dissertation, a piece of a chapter. In the present text we bring what has moved our thoughts during the development of the research, that is, the scribbles, the silences, the doubts, the emotion, the affection, the hardness, the inconsistency, the power and so on ... - Letter-article is the result of what two researchers - guiding and guiding - lived, built for two years of master's research work, but also, in post-defense continuity, two years later, during group meetings of research.

KEYWORDS: Narrative Writings, Letters; Sexuality, PIBID

$* * *$

A cada leitura uma escrita, uma busca, um encontro. Um sair de si e estar com o outro. Escrever é nunca estar só, é encontrar-se com o outro que lê. John Erlinton Simão dos Santos

\section{Iniciando a carta}

Feira de Santana, 08 de março de 2018.

Querida/o leitor/a, estamos aqui pretendendo estabelecer um contato dialógico entre a nossa escrita e sua leitura. A carta que te escrevemos é, de certa forma, constituída por um (des)caminho, que realizamos há alguns anos, ao desenvolvermos uma pesquisa de mestrado em que experimentamos o encontro entre cartas de estudantes de Licenciatura em Ciências Biológicas e a leitura delas, subsidiada por um suporte teórico e metodológico.

Digamos, desta maneira, que este "monólogo" diante da tela do computador que se inicia é, de fato, uma conversa com personagens no exercício da leitura, da escrita e da escuta que ultrapassa barreiras físicas e 
temporais. Faz parte desta narrativa dissertativa, portanto, os autores desta carta-artigo, você, as/os estudantes que contribuíram como interlocutores/as da pesquisa e as/os autoras/es que nos inspiraram para o suporte teórico. Sendo assim, não é somente nós os remetentes que você lê, mas um conjunto de ideias de pessoas cujas narrativas estão registradas nesta carta.

Iniciamos nossa escrita, primeiramente, para falarmos um pouco sobre quem te escreve, no intuito de trazer provocações e reflexões iniciais acerca da temática a ser discutida e que auxiliarão a nossa relação e na sua compreensão sobre este texto que te convidamos a ler. Passamos a narrar, de maneira breve, o eu dos autores, as implicações e caminhos que trouxeram a composição desta carta.

Um menino que não entendia direito a vida, mas que apesar de criança, percebia ser "diferente" naquele espaço tão igual ou "igualizante" palavra que inventamos para descrever como percebemos o ambiente escolar. Seríamos nós os únicos diferentes? Ou seríamos todas/os iguais por termos nossa particular diferença? Foi a partir destes questionamentos que decidimos embarcar neste trem que nos conduziriam por trilhos (ou encruzilhadas?) e em vagões largos de conhecimento, que resultaram em nossa pesquisa de mestrado.

$\mathrm{Na}$ necessidade em entendermos nosso próprio corpo e as pressões que o modelaram desde a infância e ainda o edificam, talvez esteja o ponto de partida desta curiosidade em construir perguntas e buscar respostas.

Vários âmbitos sociais como a igreja, a família, as ruas da cidade, os parques, dentre outros, nos remetem às formas de poder e saber que determinavam/determinam qual comportamento necessitaríamos/necessitamos adotar, qual corpo precisaríamos/precisamos assumir. Diante das esferas modeladoras de nossas identidades trazemos na lembrança o ambiente escolar que hoje entendemos como currículo oculto e é sobre ele que iremos debruçar nossos argumentos.

Ainda na Licenciatura, retornamos à escola, à educação básica, como professores e pudemos constatar no ambiente educacional, forças camufladas, 
bastante difíceis de serem superadas e rompidas. Regulamentado pela heteronormatividade e o binarismo de gênero, o currículo escolar domina e determina as vestimentas, os comportamentos, as práticas e os discursos de profissionais da educação e estudantes. Esta se aplica em uma tentativa de uniformização, controle, manipulação das identidades de gênero a serem vivenciadas neste local.

A nossa experiência como profissional docente possivelmente não apresente informações suficientes para uma discussão exaustiva diante da problemática apresentada. Mas, pudemos constatar nas poucas unidades escolares em que estivemos presentes que a nossa prática e de colegas, refletiam/refletem nos imperativos socioculturais que também nos atingem e dominam.

Passamos a entender também, que a universidade, no curso de formação de professores/as, assim como na pós-graduação, tem apresentado dificuldades para trazer para seus currículos as discussões diante da problemática apontada. Diante deste episódio nosso grupo de pesquisa tem buscado uma aproximação da pedagogia decolonial e intercultural crítica e o posicionamento de combate do colonialismo presente nos saberes que modelam as práticas educacionais e os modos pesquisas por meio da insubordinação e do questionamento da modernidade como propagadora das ideias de superioridade de determinados grupos sobre os demais.

Para tanto, acreditamos que diálogos como este que estamos promovendo por meio desta carta é um ponto de partida para potencializar nas discussões que ocorrem no curso de formação de profissionais da educação, além de outros espaços educativos formais e não formais, como locais de questionamento, reflexão e descobertas sobre as questões aqui apresentadas

Pensamos que nossa atuação ainda fragilizada acerca da temática em questão e a ausência da preocupação com a mesma por parte de outros/as profissionais de educação é resposta da nossa vulnerabilidade diante das "verdades" que arquitetam nossos corpos e nossas identidades. Desta forma, 
replicamos muitas vezes atitudes de escolarização e domínio, assim como nos fizeram durante nossa longa trajetória nos espaços educacionais.

Percebemos o quanto a "escolarização dos corpos" (LOURO, 2015) reflete tudo o que foi apresentado até agora, direcionando habilidades e comportamentos que expressam a "domesticação" realizada pela escola. Porém, um novo cenário vem sendo construído e anuncia resistência ao rigoroso controle que é exercido, manifestado e sinalizado sobre as sexualidades o que tem apontado para o clamor e para a visibilidade das mesmas por meio de atitudes, vestimentas e de como nos relacionamos socialmente no espaço educacional.

$\mathrm{O}$ ato de orientar essa pesquisa sobre o tema gênero e sexualidade trouxe para nós uma desestabilização, pois não bastava orientar aquele mestrando, mas também ser (auto)formado, ou seja, o exercício de orientação exigia de nós uma profunda reflexão acerca do nosso papel de professor, orientador, pesquisador e, sobretudo, gente. Não foram poucas as vezes que saímos das reuniões com mais dúvidas do que certezas. Interessante destacar que tais dúvidas não se referiam, particularmente, a aspectos teóricos ou metodológicos, mas sobre nossas vidas, aquilo que aprendemos naquele instante de (des)orientação e carregamos para nossa vida cotidiana.

Ministrando aulas de Estágio Supervisionado para futuras(os) professoras(es) de Biologia, víamos como necessidade de abordar o tema de gênero e sexualidade, mesmo que esse conteúdo não estivesse explicitamente na ementa da disciplina, mas por conta de estar presente no cotidiano das escolas que os(as) estudantes estagiavam e/ou na própria vida delas(es).

A partir dessa experiência, iniciamos o trabalho empírico de nossa pesquisa de mestrado e bolsista do Programa Institucional de Bolsa de Iniciação à Docência PIBID referente às suas vivências pessoais e acadêmicas relacionadas às questões de gênero.

\section{Entre leitura e escrita: os "eus" de uma história}


Realizamos a análise das narrativas oriundas de cartas pessoais de cinco estudantes do curso de Licenciatura em Ciências Biológicas de uma universidade pública baiana e que também eram bolsistas do Programa Institucional de Bolsa de Iniciação a Docência (PIBID). Em suas cartas, as/os estudantes registraram suas vivências pessoais e acadêmicas relacionadas às questões de gênero e suas sexualidades.

Adotando as cartas como ferramenta metodológica, nos inspiramos em Savenhago (2010) ao mencionar que ao analisar cartas é necessário fazer movimentos interpretativos e constituir pontos de vista. Nesse sentido, as cartas foram compreendidas como instrumento capaz de revelar identidades, sentimentos, saberes, as relações de poder presentes nos discursos das pessoas envolvidas.

Além disso, prezada/o leitora/or a pesquisa se pautou naquilo que Domingues (2012) e Galvão (2005) nos convidam a pensar, que as narrativas expõem as memórias atreladas a um tempo e espaço histórico e a um caráter social de algo pessoal por meio do conteúdo temático, estilo linguístico e estrutura composicional. Incorporadas ao jeito de pensar e de ser de cada sujeito, estas narrativas possibilitam a compreensão de como o indivíduo se firma e se projeta diante da realidade, o que implica uma negociação de poder e revela como somos construídos pelas histórias que contamos aos outros e a nós mesmos.

Devemos considerar que o contato estabelecido com Savenhago (2010), possibilitou reflexões transgressoras que foram de extrema importância para o amadurecimento e a descoberta das cartas como um promissor caminho metodológico. Este autor, diferente de muitos outros trabalhos que utilizaram cartas como estratégia de acesso às narrativas pessoais, além de usar cartas recentes, se dedicou aos relatos de vida e aos vestígios de experiência revelados presentes nestes documentos.

Deste modo, a carta é considerada um artefato repleto de linguagem e de signos capazes de representar e construir o real, ou seja, uma atividade 
social resultante da necessidade do ser humano em comunicar-se, de narrar e trocar suas experiências e se organizar socialmente (WATHIER, 2012).

Os argumentos que aqui são defendidos é que ao escrevermos cartas vamos colocando em evidência nossas identidades, sejam elas reais ou inventadas, para quem escrevemos. Por intermédio da escrita mostramos nossas ideias, modo de vida, crenças, dentre outros imperativos sociais e culturais. As cartas são, desta maneira, um potencial instrumento de estudo quando se busca compreender elementos históricos, culturais e identitários de um determinado grupo. Sendo assim, adotamos as experiências das/os estudantes como elemento central de nossa investigação discussão e problematização.

Convidamos você a pensar a experiência como a relação antagônica entre a (des)subjetivação dos acontecimentos saboreados e revelados pelo sujeito, como construções discursivas do próprio eu de cada indivíduo que experimenta e é experimentado a si mesmo, pelo mundo e pelo outro. A experiência é, portanto, o produto dos sujeitos no exercício de se construírem (FERRARI, 2013), "é o que nos passa, o que nos acontece, o que nos toca" (LARROSA, 2002 p.21), nos edifica, cria, transforma e nos atravessa ao mesmo instante em que é construída, experimentada e vivida.

A experiência é, então, um evento desafiante que transcende limites, mas também a estrutura histórica dominante de pensamento, ação e sentimento que será desafiada (LEARY,2012 p. 877), que implica o sujeito desprender-se de si mesmo para sua alta produção, numa ética e estética de existência; é o questionar e refletir de si e do mundo, em relação ao que se é, ao que se pensa, transformando-o em objeto da experiência e que experimenta (FOUCAULT, 2006).

Desse modo cara/o leitora/or, o sentido de experiência que adotamos e mostramos aqui nessa carta-artigo diz respeito à realidade quanto à apreensão subjetiva que (trans)forma os sujeitos. Isso possibilita confirmar o que já é conhecido por meio das verdades e relações de poder que nos indicam o que ver e como ver, mas também ajusta nossas visões diante dos conflitos e 
questionamentos do que parecia "óbvio". Neste local encontra-se o tomar de consciência do processo de mudança e aprendizagem com as experiências que constituem nossas histórias.

Observamos que as/os estudante/s, foram ao mesmo tempo narradoras/es e personagens de suas histórias e isso nos permitiu o contato com suas narrativas e a maneira que entendem e vivem suas sexualidades. Elas/es nos emprestaram seus olhos, seus pensamentos e palavras que revelavam suas histórias. Enquanto pesquisadores fomos apenas os "condutores" que convida os sujeitos adentrarem nesta viagem. Esta situação nos aproxima dos atos e vivências dos indivíduos da pesquisa, porém, aqui expressamos a opinião de que muito vai se perdendo ao longo do caminho, restando como resultado este encontro entre você, a nossa escrita, as cartas das/os estudantes e as cicatrizes deixadas por suas experiências reveladas por intermédio de suas memórias e narrativas.

O posicionamento aqui adotado é que as experiências não podem e aqui não são reveladas e cedidas, elas são apenas vividas. Para tanto, a intenção em demarcar o registro das narrativas das/os pibidianas/os foi promovida pela possibilidade de trazer suas memórias associadas a um tempo e espaço histórico. Com isso buscou-se traços das experiências vividas na infância e ao logo dos caminhos percorridos em sua formação familiar, escolar e acadêmica, com interesse nos fatos do passado, mas também, como estes interferem na maneira como se projetam no presente, de como estas experiências continuam sendo incorporadas na maneira de ser, pensar e fazer das/dos estudantes, de como se lançam diante das questões e desafios da realidade, modelam seus saberes e deixam marcas, sobretudo, em sua identidade profissional (DOMINGUES, 2012).

As/os licenciandas/os puderam narrar o mundo e se colocaram em suas narrativas, estabelecendo uma relação entre o espaço, o tempo histórico e os personagens de suas histórias.

Neste direcionamento, cara/o leitor/a, Domingues (2012) afirma que a narrativa é revelada como a reprodução do mundo na qual a memória é 
carregada de representações e linguagens e torna-se parte da identidade e da essência do sujeito, o que requer posicionamento, liberdade e capacidade de refletir e agir sobre o mundo.

Tomando como suporte estes argumentos afirmamos que foi apresentado nas cartas das/os estudantes um mundo real imbricado a uma realidade possível. O que queremos te dizer é que as/os pibidianas/os revelaram vestígios de suas experiências em suas narrativas, mas a estas, associaram suas perspectivas, sonhos e idealizações futuras. Participar desta pesquisa e escrever cartas sobre suas vidas possibilitou a elas/es reviverem fatos ocorridos em suas vidas, sobre as questões de gênero e suas sexualidades, por intermédio da memória.

A partir da próxima parte desta carta-artigo, trazemos para você a maneira que os saberes das/os estudantes acerca da sexualidade são transgredidos, vividos e reafirmados na universidade. As escritas das/dos pibidianas/os apontam como a sexualidade atravessa o chão da escola ou da universidade e divulgam seus saberes, opiniões, visão de mundo e aspirações profissionais referentes à temática em questão.

\section{O ajustar da vida vivida com a vida desenhada sobre a folha de papel}

Ao oferecermos a você a desafiadora ação de transformar a si a partir da leitura do que escrevemos nesta carta, procuramos expor as fagulhas de experiência ao entrar em contato com a escrita das/os pibidianas/os, ao fazer movimentos interpretativos e constituir pontos de vista sobre a mesma. Firmamo-nos diante da realidade que se projeta por meio da negociação em construir e revelar o "eu" que leu as cartas transgredido no "eu" que agora escreve para você.

Ao caminhar sem rumo sobre as linhas traçadas de cada carta, fomos acessando o mundo invisível, real/fictício, vivido e (re)construído por cada estudante que escreveu, se (re)inventou em um universo de letras e palavras pintado de cores variadas. Ao trilhar sobre as narrativas das estudantes 
pudemos acessar os múltiplos sentidos de si e as suas variadas compreensões de suas sexualidades.

As/os estudantes escreveram histórias em suas cartas e as fizeram nelas, ajustaram a vida vivida com a vida desenhada sobre a folha de papel tornando-as uma só, registraram um passeio sobre os fatos com letras bonitas, intensas e cheias de possibilidades, oferecendo caixas transbordadas em encontro com suas memórias, suas perspectivas e suas escritas de si e do mundo.

Atravessadas/os e interpeladas/os pelo inconsciente, as/os remetentes das cartas, confessaram suas existências costurando memórias em uma escrita de si, mapeando e recolhendo os fragmentos de suas histórias presentes nas narrativas e isso possibilitou o exercício da autorreflexão por meio do texto narrado. Caminhos foram traçados em forma de labirintos e deslocamentos identitários expondo os "eus" que nunca foram uno, que ora se reconhece ou se estranha diante de quem escreve e de si ao construírem possibilidades e desejos de identificação (FERREIRA, 2012).

Seguindo esta lógica, nos deparamos com os dizeres de Castro (2014) que aponta que aescritada experiência ao ser produzida transforma a quem escreve pelo que é narrado. Desta maneira, consideramos que as/os autoras/es que fizeram parte da pesquisa foram (re)feitas, transgredidas pelas marcas dadas e causadas pelas experiências de cada escrita, pois consideramos que ao experimentarem e ao lançarem o olhar às memórias explícitas em suas narrativas, ao contar suas histórias, mudaram, porque a própria experiência em repensarem as suas vidas e ao lançarem o olhar sobre o passado e/ou expectativas futuras, passaram pelo processo de transformação.

Prezada/o leitora/or desse artigo-carta, gostaríamos de reiterar que não apenas as/os licenciandas/os que narraram as curvas de suas vidas sobre linhas retas do papel foram (re)inventadas, também nós, os primeiros/as destinatários, fomos e estamos em uma contínua reconstrução de nós mesmos. Você, agora, passa a ser a/o nova/o destinatária/o e, pela leitura dos escritos 
narrativos aqui registrados, pretendemos que possa ser te conduzida/o à reflexão e ressignificação dos fatos.

Sob este ponto de vista, as correspondências utilizadas como dados para análise da dissertação e esta carta-artigo que te escrevemos são compreendidas como um texto que transcorre os limites da linguagem. Tem a escrita de cartas o domínio em conduzir tanto quem escreve quanto quem lê a repensarem de maneira cautelosa as suas vivências, recriando-se e transpondo as fronteiras do que são (IONTA, 2011).

Foucault (1992) nos convida a pensar que o texto destinado a alguém dá espaço à exposição pessoal de quem envia e de quem recebe, sobrepondo, o nosso adestramento pelo que escrevemos e lemos. As cartas, construídas pelas/os estudantes, operaram sobre elas mesmas pelos caminhos traçados no gesto da escrita, configurando-se como uma maneira de se arremessarem e fazerem-se presentes de maneira imediata e quase física a quem se dirige.

As cartas ainda atuam sobre quem as recebe por meio da prática de sua leitura e releitura e pelo envolvimento de quem a escreve que oferece seu olhar no que diz de si estabelecendo uma face-a-face, emaranhando o eu de si com o eu do outro.

Desse modo, foram convidadas/os as/os licenciandas/os para escreverem as cartas e nós, pesquisadores, a avaliarmos os fenômenos acerca da sexualidade e das identidades de gênero que permeiam nossas vidas, o que atravessa nossas almas e corpos por meio do que escrevemos e agora, você leitor/a dessa carta-artigo.

Para a escrita dessa carta-artigo misturamos nossas histórias narradas, apresentamos fragmentos de memória incorporados ao nosso jeito de ser, de pensar e se relacionar com a temática da pesquisa. De tal modo, nos dedicamos em problematizar acerca dos possíveis imperativos culturais, religiosos, costumes, hábitos, formas de ser, de agir e sentir, tensões, opiniões, desejos e sentimentos, imbricados nas narrativas das estudantes. Não foram verdades e/ou reconstruções de uma realidade de fatos e acontecimentos que se esperou encontrar nos escritos, mas o aflorar das experiências vividas e a 
interpretação de gestos de escritas no processo de subjetivação, que possibilitou a compreensão de como as/os estudantes se firmam e se projetam diante da realidade, de como se revelam, constroem e se editam diante e pelas escritas de si contadas a elas mesmas e aos outros.

Durante a leitura das cartas não identificamos se as/os destinatárias/os eram pessoas reais ou fictícias, criadas para serem interlocutoras/es dos seus desabafos, dúvidas. Para preservarem suas identidades, as/os pibidianos/as escolheram um nome fictício para assinar suas cartas: Lucia escreveu para sua tia Ana; Lucas designou as suas cartas a um querido professor; Suan escreveu para o amigo Lupi; Silvia destinou as cartas para os pesquisadores e Ilka, ao querido primo Lucca.

As cartas escritas ganharam força na pesquisa, transformadas em artefatos importantes do qual pudemos extrair informações necessárias para alcançar os objetivos esperados. Seguimos a nossa viagem trilhando sobre as cartas que tiveram como direcionamento a percepção das/os licenciandas/os sobre gênero e suas sexualidades. Guiados pelos rastros deixados por quem as escreveu fomos direcionados às experiências, memórias, afetos, reflexões e projeção de si sobre a folha de papel escrita, repleta de sentidos e significados. Para tanto, foram derramadas sobre o branco da tela do nosso computador letras coloridas que representaram o híbrido dos eus das/os estudantes entrelaçados aos eus que colorem este texto produzido em formato de cartaartigo e que seus olhos agora leem.

As/os estudantes utilizaram o momento e a oportunidade de sua escrita para expor os desafios a serem enfrentados e refletiram sobre as posturas a serem tomadas quando se tornarem profissionais de ensino; relataram e reviveram em suas mentes fatos observados e experimentados no dia-a-dia, sejam na universidade ou fora dele, acerca dos gêneros e sexualidades.

Argumentaram também sobre a importância da universidade e do PIBID em suas formações e como o contato com estes locais de formação podem contribuir para possíveis abordagens envolvendo questões ligadas à sexualidade em seus futuros ambientes de trabalho. 
Identificarmos nas cartas vestígios de experiências das estudantes investigadas e a maneira que compreendem e constroem seus saberes sobre as identidades de gênero e sua relação com a formação e a prática docente. Percebemos também fortes argumentos sob a necessidade do posicionamento mais efetivo da universidade por meio dos cursos regulares, principalmente as Licenciaturas, e/ou pelo PIBID, na oferta de ações que contribuam para o encorajamento, na busca de saberes que auxiliem suas práticas atendendo às exigências acerca das questões de gênero e sexualidades nos espaços escolares e, do mesmo modo, as cartas registraram que os cursos de formação de professores/as são potentes na problematização destas questões.

Assumimos desta maneira a posição de que ao pensar a sexualidade para ser um tema abordado nas escolas, devemos ponderar a organização e atuação curricular das instituições de ensino superior, pois são lugares predominantes das produções científicas que muitas vezes estabelecem os rumos da sociedade e que profissionalizam os indivíduos que irão cumprir a função de educadores/as e/ou discutirão construirão/reformarão os currículos.

\section{Agora são elas/eles que você lê}

Cara/o leitor/a, após trazer uma análise geral do que identificamos nas escritas das/os estudantes, apresentamos a vocês alguns trechos das cartas, possibilitando o contato direto entre você e a escrita das/os futuras/os professoras/es. As/os estudantes falam sobre a infância; período na escola; relações amorosas; questões religiosas, dentre outras, que escolhemos trazer aqui apenas o que está relacionado com a formação e a prática como bolsista do PIBID. Optamos por nos pronunciar pouco, a partir de então, numa tentativa de que a voz das/os estudantes, apareça mais nesta carta-artigo em que elas/es também são escritoras/es. Desta maneira, não trouxemos todas as discussões e análises feitas na dissertação, no intuito de provocar, você leitor/ra, a um diálogo e à transformação de si, a partir do contato com as cartas, bem como convidá-lo/a a ler a dissertação. 
Dentre os dizeres nas escritas das/os estudantes chamou-nos a atenção o fato de afirmarem que não se sentem confortáveis em abordarem sobre as questões de gênero e que não saberiam qual atitude tomar diante de situações conflituosas acerca da sexualidade tão presentes no ambiente escolar:

Durante algumas atividades do PIBID vejo muito os estudantes debocharem de um garoto falando que ele parece uma mulherzinha, eu fico sem reação, não sei o que fazer, e o pior que este estudante fica sempre isolado, nunca participa de minhas intervenções.(Lucas)

Em certa aula que ministrava para o ensino médio surgiu a discussão sobre homossexualidade, e um dos garotos de maneira bem agressiva começou a falar "que os gays deveriam morrer e se tivesse algum colega gay ele espancaria”. Fiquei muito assustada e com sentimento de fragilidade. O que fazer em casos como este? Sinceramente eu não sei, mudei de assunto e fingi que não ouvi aquela barbaridade. (Ilka)

Muito pode ser discutido a partir destes dizeres e você possivelmente deve estar agora imaginando as causas destes fatos, pensando em quais medidas tomar para os problemas explícitos. Este é também o objetivo desta carta-artigo, provocar estas sensações.

Talvez você, assim como nós, tenha identificado que estes enunciados mostram uma realidade vivenciada pelo/a pibidiana/o, que se assemelha a de muitas outras/os licenciandas/os. A/o estudante revela o distanciamento como possível mediadora/or nas discussões acerca da sexualidade humana e como agentes de (in)formação das crianças e adolescentes que crescem em uma sociedade com práticas constantes de violência física e simbólica contra as mulheres, gays, lésbicas, travestis, transexuais e transgêneros e várias outras formas de vivermos nossas sexualidades.

Outro fato curioso é que as/os estudantes descreveram em suas cartas demonstrando o interesse em realizar atividade sobre sexualidade no PIBID e/ou em sala de aula quando forem professoras/es e acreditam ser necessária 
a realização das mesmas. Contrapondo a esta informação, sinalizaram nunca terem desenvolvidos tais atividades, justificando tais empecilhos:

Olha, eu até gostaria de realizar oficinas sobre a sexualidade no PIBID, mas não faço porque é um tema polêmico. (Silvia)

Eu não saberia lidar com os preconceitos que são construídos pela sociedade, então é melhor não me envolver e piorar as coisas. (Suan)

Tenho medo do que os pais e até mesmo os professores vão achar. Lembro do meu tempo como estudante de ensino médio que a professora de Biologia sempre falava que este assunto ainda é visto como proibido e que tinha muito cuidado no que iria abordar. (Ilka)

Não me sinto motivado e seguro para a promoção de uma reflexão sobre os assuntos, sobre gênero e sexualidade na escola, acho que deveria existir profissionais especializados para isso. (Lucas)

Eu não acho que este tema deva ser discutido no PIBID, nem mesmo na escola. Os estudantes devem aprender conteúdos relevantes para a vida deles, para o vestibular, por exemplo. (Lucia)

Além dos vários motivos mencionados pelas/os estudantes em não trabalhar com sexualidade, elas/es julgam a ausência de uma formação acadêmica com discussões, debates e/ou esclarecimento sobre o tema como um dos impasses. Mas ao mesmo tempo identificam a importância da universidade e da formação para que possam promover atividade que envolva a temática da sexualidade:

Eu não tive uma formação adequada, então eu não trabalho com sexualidade por não ter conhecimento que me dê suporte (...) Seria ideal se a universidade orientasse a gente. (Silvia)

Tenho receio e certo medo de trabalhar com estes assuntos, até porque nunca fui instruída pelos meus pais, escolas ou universidade sobre o assunto, por isso eu sempre 
me pergunto por que os professores não pensam em uma disciplina nesse caráter aqui na Universidade. (Ilka)

Não recebi formação adequada que me possibilite trabalhar com sexualidade(...) ainda bem que na disciplina de estágios às vezes o professor fala destas coisas. (Lucas)

Durante o curso em Licenciatura em Biologia não existe uma disciplina apropriada para discutir sobre estes assuntos. (Lucia)

Cara/o leitora/or a partir destes dizeres podemos chegar a várias interpretações e você tem total liberdade para isso. Nós, por exemplo, identificamos nos discursos produzidos pelas/los discentes que o curso de formação investigado, apresenta lacunas quando se trata da abordagem sobre gênero e diversidade sexual. Nos parece que a sexualidade e discussões sobre desigualdade de gênero, por exemplo, encontram-se à "margem" do currículo escolar e da formação de professores/as da instituição dessas/es estudantes, embora não possamos afirmar que esta não esteja presente.

Isso nos leva a imaginar que há também uma falta de interesse de as pessoas procurarem outros meios de informação e aprendizagem, seja em minicursos, leitura de artigos científicos, participação em congressos etc, ou seja, outros espaços formativos.

Outra situação fortemente apresentada nas cartas é a restrição da sexualidade por parte das/os estudantes a aspectos exclusivamente anatômicos. É imerso neste contexto de conhecimento científico, biológico, "descontextualizado" e distante das questões culturais e sociais acerca da sexualidade que estão os escritos das/os estudantes de Biologia apresentados abaixo:

É necessário um homem e uma mulher para existir uma criança, ou seja, precisa da célula gamética do homem e da mulher, isso é uma relação normal (...) Para mim é inexplicável a relação entre pessoas do mesmo sexo, primeiramente como a espécie humana vai se perpetuar? (...) Como gosto muito de zoologia explicaria as diferentes 
maneiras que os animais se desenvolvem desde a fecundação ao nascimento. Acho que falar sobre sexualidade na escola tem que ser sobre estes assuntos. Acho os estudantes gostariam muito de ter aulas deste tipo. (Lucia) (Grifo nosso)

Devido ao alto indice de doenças sexualmente transmissiveis, acho que trabalharia com os estudantes explicando a necessidade de usar preservativos para não adquirilas e também para não surgir uma gravidez indesejada. Por fim, falaria dos vírus que são causadores destas doenças. (Suan)

Como trabalhamos com um público jovem e muitos deles estão iniciando a vida sexual, outros não, convidaria pessoas para dar palestra sobre virgindade e as mudanças de fase na adolescência; depois discutiria com eles em sala de aula sobre o que aprenderam. (Ilka)

Faria um jogo de memória ou quebra cabeça com as partes anatômicas dos homens e das mulheres. Neste jogo eles teriam que saber os nomes das partes e a quem pertenciam.(Lucas)

Os assuntos mencionados pelo/as futuro/as professor/as são de relevância no ensino de Biologia, porém, o agravante se encontra no caráter da abordagem em uma perspectiva estritamente fisiológica, deixando de lado os elementos culturais, sociais, históricos por trás destes conteúdos e, principalmente, a ausência de discussões diante das pressões que nos inventam homens e mulheres, heterossexuais e homossexuais, por exemplo. Torna-se preocupante a ausência de uma postura crítica diante do cientificismo e de suas "verdades" para compreensão do mundo de maneira descontextualizada.

Uma das estudantes apresenta ainda a ideia negativa sobre a/o professora/or ao desenvolver trabalhos em sala de aula valorizando as diferenças sexuais, como a homossexualidade, estimular as crianças e adolescentes a adotarem tal comportamento:

É um absurdo que um professor fique discutindo sobre homossexulidade em sala de aula e, pior ainda, que deixe evidente que é homossexual. Tudo bem que tenha feito 
sua escolha, mas acredito ser antiético sair se expondo no ambiente de trabalho influenciando a mudança de personalidade dos estudantes, estimulando os estudantes serem gay. Isso é digno de demissão por justa causa (Lucia)

Essa postura tomada pela estudante nos convida a sérias reflexões. Possivelmente, assim como nós, você deve estar se fazendo várias perguntas: Qual atitude tomará esta futura professora ao ter um/a estudante homossexual, dentre outras maneiras de expressão das sexualidades? Qual postura será difundida em sua prática em sala de aula? Quantas "Lucias" temos dentro das salas de aula? Estas e muitas outras interrogações que convidamos você a refletir e buscar por um processo de trans(formação).

Em meio aos variados saberes que circundam as identidades de gênero na contemporaneidade e suas múltiplas e inconstantes maneiras de serem vividas, experimentadas, provoca abalos nas estruturas padronizadas que nos fazem homens e mulheres e isso possivelmente mexe com Lucas, com sua maneira de ver e viver o mundo. $\mathrm{O}$ estudante refere-se ao professor como um porto que possa ajudá-lo a compreender o novo que se espalha em nossa cultura, identifica alguém com que possa expor suas ideias e compartilhar saberes. Perdido em meio às informações, à inconstância identitária, o romper de padrões e o encurtar das diferenças entre homens e mulheres o estudante parece considerar a luta por igualdade de direitos sociais e culturais desnecessária.

\section{Despedida}

Os textos escritos não são fruto apenas do que os escritores querem dizer, mas também do que eles supõem ser de interesse dos leitores. Há um 'contrato' implícito entre autor e leitor. Quem escreve imagina um leitor empenhado em compreender o que o texto diz: nenhum texto é suficientemente

bom para dispensar o necessário exercício de atribuição de sentido por parte de quem lê. Os leitores, por sua vez, esperam 
que os autores estejam dizendo algo de fato interessante, algo que vale a pena ler.

(Rosaura Soligo)

Desta maneira buscamos escrever esta carta-artigo no intuito que a escrita de nossas vidas nos possibilitasse acolher nosso estar, inventar modos de ser, descobrir outro(s) eu(s) que coexistem e produzem marcas em nossos corpos (SILVEIRA e FERREIRA, 2013). Chegamos ao fim ou talvez um novo ponto de partida com a sensação que ao escrever para você nos possibilitou sair de nós mesmos para estar em encontro com tantas/os outras/os pessoas em um estado de transformação. Podemos concluir esta carta-artigo que já não somos mais os mesmos quando iniciamos esta escrita e supomos que você já não seja mais a mesma/o ao finalizar esta leitura.

Diante do que apresentamos nessa carta-artigo, queremos mostrar, sobretudo, que defendemos que as estratégias para abordar a sexualidade e gênero nas escolas da rede básica de ensino devem estar atreladas à formação das/os professores/as. Acreditamos que os centros acadêmicos têm condições necessárias, competência e responsabilidade nos encaminhamentos para a formação de docentes conscientes dos confrontos a serem enfrentados em suas práticas cotidianas e capazes de suavizar e/ou abolir os conflitos gerados pela intolerância à diversidade presente na escola e na sociedade por meio do diálogo, do debate e reflexões acerca das situações de discriminação e desigualdade.

Assumimos o posicionamento político de que por meio da formação reflexiva de educadoras/es acerca das sexualidades e gêneros é que possivelmente alcançaremos uma atuação docente que garanta a todas/os os/as alunas/os o direito a uma educação, livre de preconceito e violência e questionadora dos imperativos que padronizam e corrompem nossas identidades através dos processos de normatização de nossos corpos e de nossos comportamentos.

Assim chegamos a nosso destino final e sem dúvida que esta carta-artigo contribuiu para nós e assim esperamos que possibilite a cada leitora/or 
importantes momentos de reflexão que motive um novo percurso a ser traçado.

\section{Referências}

CASTRO, R. P. Formação docente para as relações de gênero e sexualidades: problematizando a heteronormatividade no Ensino Superior. Rev. Periódicus,

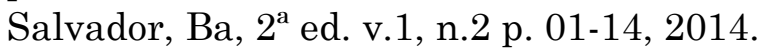

DOMINGUES, G.S. Cartas ao professor: narrativas discentes sobre o trabalho docente. ENCONTRO NACIONAL DE DIDÁTICA E PRÁTICAS DE ENSINO, 16, 2012 Campinas. Anais do $16^{\circ}$ Encontro Nacional de Didática e Práticas de Ensino. Campinas, Universidade Estadual de Campinas, 2012.

FERRARI, A. A potencialidade do conceito de experiência para a educação. Juiz de Fora, MG: Editora UFJF, 2013.

FERREIRA, G. G. A Escrita de si como labirinto na construção da identidade profissional docente. Rev. Travessias, Florianópolis, SC, v.6, n.1, p. 220-233, 2012.

FOUCAULT, Michel Ética, Sexualidade, Política. Ditos \& Escritos.v. 5 ed. 2 Org. MOTA, M. B. Rio de Janeiro, RJ: Forense Universitária, 2006. 1992.

A escrita de si. In: O que é um autor? Veja Passagens. Lisboa, p. 129-160,

GALVÃO, C. Narrativas em educação. Rev. Ciência e Educação. São Paulo, SP, v.11, n2, p. 327-345,2005.

IONTA, M. A Escrita de si como prática de uma literatura menor: Cartas de Anita Malfatti a Mário de Andrade. Rev. Estudos Feministas, Florianópolis, Sc, v.19, n.1, p. 91-101, 2011.

LARROSA, J. Notas sobre a experiência e o saber da experiência. Revista Brasileira de Educação, Rio de Janeiro, RJ, n. 19, p. 20-28, 2002.

LEARYV, T. O. Foucault, experiência, literature. Antíteses,Londrina, PR, n. 5, v. 10, p. 875-896, 2012.

LOURO, G. L. Gênero, Sexualidade e Educação: Uma perspectiva pós-estruturalista. Petrópolis, RJ: Vozes, 2015. p. 184.

SAVENHAGO, I. J. S. Análise discursiva de cartas da prisão: uma discussão sobre ciência e saberes.Linguagens e Diálogos, Rio de Janeiro, RJ, v. 1, n. 2, p. 73-89, 2010. 
SILVEIRA, M.; FERREIRA, L. H. Escritas de si, escritas do mundo: um olhar clínico em direção à escrita. Rev. Athenea Digital, São Leopoldo, Rs, V.13, n.3, p.243-263, 2013.

SOLIGO, S. Cartas pedagógicas sobre a docência, SP: GFK, 2016.

Recebido em março de 2018.

Aprovado em dezembro de 2018. 